\title{
Multifocal epithelial hyperplasia, a rare oral infection in Asia: Report of twelve cases in Iran
}

\author{
Pegah Mosannen-Mozaffari, Farnaz Falaki, Maryam Amirchaghmaghi, Atessa Pakfetrat, Zohre Dalirsani, \\ Shadi Saghafi-khadem
}

Assistant professor of Oral Pathology, Mashhad University Of Medical Sciences, Oral Medicine Department, Research Center of Mashhad Dental School, Azadi SQR, Mashhad, Iran

Correspondence:

Oral Medicine Department

Research Center of Mashhad Dental School

No: 91735, Vakil Abad BLV

Azadi SQR, Mashhad, Iran

FalakiF@mums.ac.ir

Received: 06/06/2009

Accepted: 28/11/2009

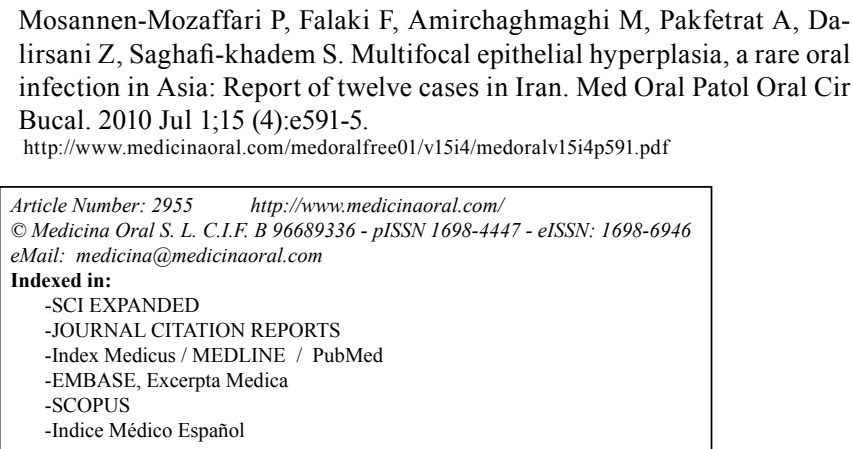

\begin{abstract}
Objectives: Multifocal epithelial hyperplasia (MEH) is benign, asymptomatic oral disease with viral etiology. The frequency of this disease varies widely from one geographic region to another, and can vary, from 0.002 to $35 \%$ depending on the population studied.

Study design: Here we report the clinicopathological features of twelve cases of MEH referred to Oral Medicine Department of Mashhad Dental School for the first time in Iran. Records of patients with the diagnosis of MEH in our department during 7 years were analyzed and data were extracted.

Results: Most of the patients were younger than 20-year-old (66\%), and females were predominantly affected (7:12). The mean age of onset was $12.72 \pm 10.14$ years and the mean duration was $52.54 \pm 78.51$ months. Patients had multiple, well circumscribed, soft, non tender, flattened papules, with a color similar to the adjacent mucosa, in different areas of the oral cavity but the most affected site was buccal mucosa. Familial history of such lesions was negative in all patients. Only three cases showed spontaneous regression.

Conclusion: In spite of rare nature of this disease in Asia, it seems that it is not the case in Khorasan Province, southeast Iran.
\end{abstract}

Key words: Focal epithelial hyperplasia, human papilloma virus, Heck's disease, Iran, case report, oral medicine. 


\section{Introduction}

Multifocal epithelial hyperplasia (MEH), previously known as focal epithelial hyperplasia (FEH, Heck's disease) is a relatively rare disease of the oral cavity in most countries (1).

It was first described by Estrada (1) in a Colombian Indian population and several reports from different countries have been published there after (2). The lesions appear as multiple, circumscribed, soft, non tender, flattened or rounded papules, with a color similar to the adjacent mucosa or a whitish color (1). Surface of the lesions is smooth and it varies from $0.1 \mathrm{~cm}$ to $1 \mathrm{~cm}$ in size, although papules may coalesce and give raise to a cobblestone appearance, several centimeters in diameter (3). In some cases a papillomatous surface has been reported (4). Flaitz has suggested compromised occlusion and sucking behavior as a cofactor in dissemination (4). The most common sites of involvement are the lips, buccal mucosa and the tongue, but in rare occasions soft palate or floor of the mouth may also be involved (4-6). The diagnosis is based on the clinical findings.

Histological findings consist of parakeratosis and acanthosis of epithelium which is the hallmark of focal epithelial hyperplasia. The ridges are widened, often confluent and sometimes club shaped (7). Koilocytic changes, similar to that seen in other HPV infections and nuclear degeneration resembling a mitotic figure (mitosoid cell), are the evidences for viral etiology $(1,2)$.

Viral etiology was first suggested by Estrada and further investigators confirmed this hypothesis (8). Molecular techniques such as polymerase chain reaction (PCR) or in-situ hybridization can be used to examine the presence of human papilloma virus (HPV) in many instances. The most common associated subtypes are 13, 32, although Cross reaction with other subtypes $(6,11,16,8,55)$ has also been reported $(1,3,7)$.

Certain HLA subtypes have been related to this disease (9). Immunohistochemical analysis for cytokeratines has been performed on MEH lesions but the results were nonspecific like every other acanthotic epithelial lesion in oral cavity (2).

No treatment is necessary because of the regressive nature of the disease $(1,3,7)$, unless in the case of interference with function or aesthetic (6). Surgical excision, electrosurgery, cryosurgery, sulfonamides, vitamin A, $\mathrm{Co} 2$ laser and alfa- $2 \mathrm{~b}$ interferon are suggested treatments $(1,3,10)$.

Generally MEH is a very rare disease in Asia. We report 12 cases of MEH referred to Oral Medicine Department of Mashhad Dental Faculty. All of our patients were resident of Khorasan Province (Northeast, Iran).

\section{Materials and Methods}

In this retrospective study, records of twelve patients with the diagnosis of MEH were extracted from the ar- chive of Oral Medicine Department of Mashhad Dental Faculty from December 2002 to March 2009 and demographic information, clinical features and histopathological characteristics of patients were recorded.

\section{Results}

Twelve cases of MEH were recorded that 7 cases were female and 5 were male. The age of our patients were between 8 to 43 years of age; with the mean age of $19.50 \pm$ 13.04 (F: $16.57 \pm 8.10, \mathrm{M}: 23.60 \pm 18.25$ ). All the patients were otherwise healthy and from a middle socioeconomic group.

\section{Clinical features}

The predominant clinical feature in our patients consisted of multiple, well circumscribed, soft, flat top papules (Fig. 1 pt no. 3) In three cases, white color appearance was seen in buccal mucosa as a result of frictional keratosis. In others, the color was similar to adjacent mucosa. The most affected site was buccal mucosa, especially across the occlusal plan, (all of our patients), followed by lip mucosa or commissure (8:12 cases). One patient did not remember the exact time of appearance of lesions. Of the 11 reminders, the age of onset was from 7 to 42 years and the mean age at onset was $12.72 \pm 10.14$ years. The duration of the lesions was from 2 months (a 9 year-old female) to 22 years (a 32 year-old female).

The mean duration time was $52.54 \pm 78.51$ months, approximately 4.5 years in 11 cases. There were not any other oral lesions in our patients. Only in 2 patients spontaneous regression was observed. Familial history of such lesions was negative in all patients. The clinical characteristics are summarized in (Table 1).

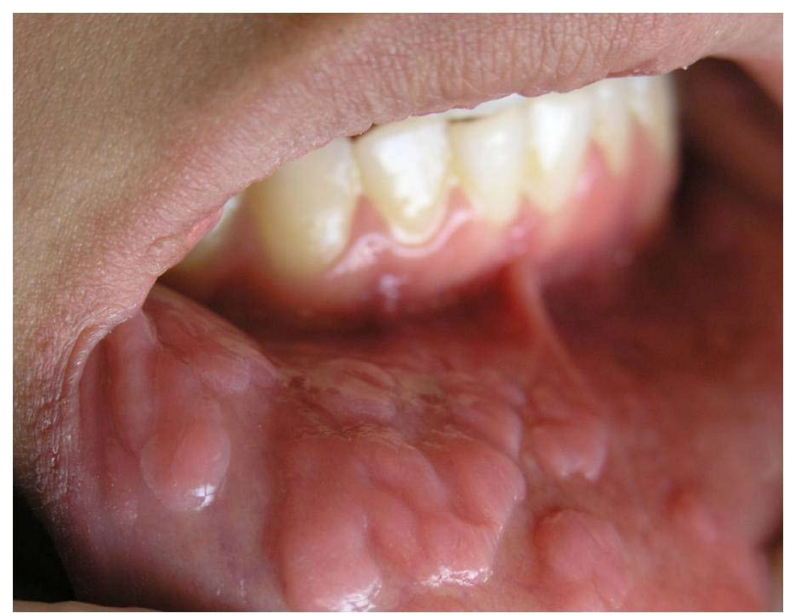

Fig. 1. Multiple, soft, well circumscribed, flat papules on labial mucosa and lip commissure of Pt. No.3. 
Table 1. Characteristics of lesions clinically diagnosed as MEH disease.

\begin{tabular}{|c|c|c|c|c|c|c|c|}
\hline Case & Age & Sex & Site & Age of onset & Duration & Regression & $\begin{array}{c}\text { Association } \\
\text { with HPV(type) }\end{array}$ \\
\hline 1 & 12 & $\mathrm{~F}$ & $\begin{array}{l}\text { Buccal mucosa, Lower lip mu- } \\
\text { cosa and commissure }\end{array}$ & 11 & 6 months & No & Yes(13) \\
\hline 2 & 13 & $\mathrm{~F}$ & $\begin{array}{l}\text { Buccal mucosa, Lower and up- } \\
\text { per lip mucosa, Retromolar pad }\end{array}$ & 13 & 1 month & $\begin{array}{l}\text { Yes(complete } \\
\text {,after } 2 \text { years) }\end{array}$ & Yes(32) \\
\hline 3 & 15 & $\mathrm{~F}$ & $\begin{array}{l}\text { Buccal mucosa, Lateral border } \\
\text { of the tongue, Attached gingiva }\end{array}$ & 7 & 8 years & No & Yes(13) \\
\hline 4 & 12 & $\mathrm{~F}$ & $\begin{array}{l}\text { Buccal mucosa, Lip commis- } \\
\text { sure, Retromolar pad }\end{array}$ & 7 & 5 years & $\begin{array}{l}\text { Yes( complete } \\
\text {,after } 5 \text { years) }\end{array}$ & Yes * \\
\hline 5 & 13 & M & $\begin{array}{l}\text { Buccal mucosa, Lip commis- } \\
\text { sure Hard palate, Attached } \\
\text { Gingiva }\end{array}$ & 13 & 3 months & Yes(relatively) & Yes(13) \\
\hline 6 & 9 & $\mathrm{~F}$ & $\begin{array}{l}\text { Buccal mucosa, Lateral border } \\
\text { and dorsal of tongue }\end{array}$ & 9 & 2 months & No & Yes(13) \\
\hline 7 & 43 & M & $\begin{array}{l}\text { Buccal mucosa, lateral boder of } \\
\text { tongue }\end{array}$ & 42 & 6 months & No & Yes(13) \\
\hline 8 & 32 & $\mathrm{~F}$ & $\begin{array}{l}\text { Buccal mucosa, lateral boder of } \\
\text { tongue }\end{array}$ & 10 & 22 years & No & $\mathrm{N}-\mathrm{A}$ \\
\hline 9 & 44 & M & Buccal mucosa & $?$ & $\begin{array}{l}\text { Not deter- } \\
\text { mined }\end{array}$ & No & $\mathrm{N}-\mathrm{A}$ \\
\hline 10 & 23 & $\mathrm{~F}$ & $\begin{array}{l}\text { Buccal mocusa, Lower lip mu- } \\
\text { cosa, Attached gingiva }\end{array}$ & 15 & 7 years & No & $\mathrm{N}-\mathrm{A}$ \\
\hline 11 & 10 & M & $\begin{array}{l}\text { Buccal mucosa, Lower lip mu- } \\
\text { cosa and commissure }\end{array}$ & 6 & 4 years & No & $\mathrm{N}-\mathrm{A}$ \\
\hline 12 & 8 & M & $\begin{array}{l}\text { Buccal mucosa, Lower and } \\
\text { upper lip mucosa and commis- } \\
\text { sure, Attached Gingiva, Floor of } \\
\text { the mouth }\end{array}$ & 7 & 8 months & No & $\mathrm{N}-\mathrm{A}$ \\
\hline
\end{tabular}

*This sample was strongly positive for HPV but none of 13,32,16 and 18 subtypes were positive.

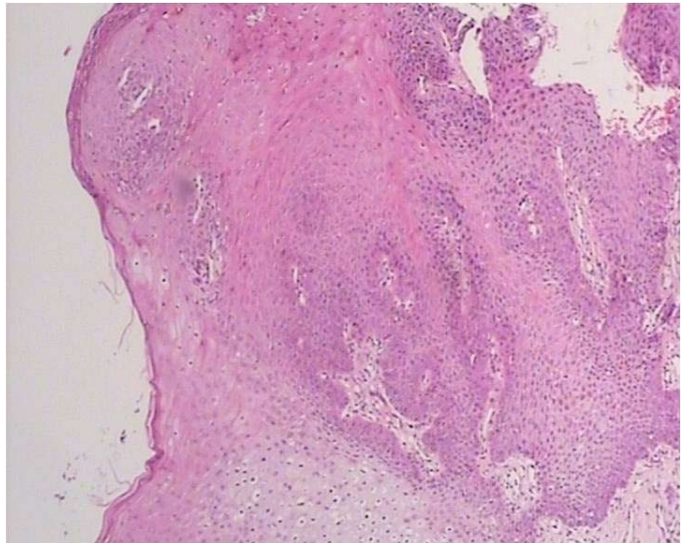

Fig. 2. Acanthosis of the epithelium with broad and elongated rete ridges $(\times 100$ Magnification, $H \& E)$.

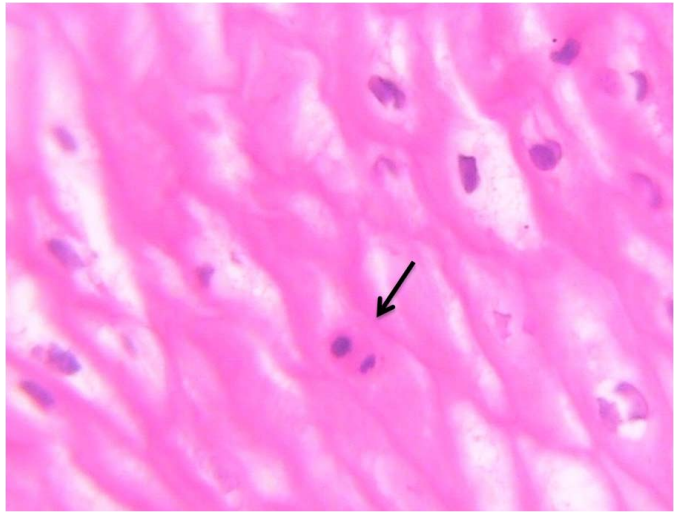

Fig. 3. Mitosoid figure a highly diagnostic feature of $\mathrm{MEH}$ ( $\times 400$ Magnifications, H\&E). 


\section{Histopathological findings}

Acanthosis of the oral epithelium was the constant finding. Reteridges were widened confluent and at the same depth of adjacenct normal reteridges. (Fig. 2 pt no.3).

In three patients orthokeratinization of superficial epithelium was oblivious.

In 7:12 of patients PCR was performed to determine presence of HPV. It was positive in all of patients. Subtype 13 was detected in five patients and 32 in one patient. In one patient with strong reactivity for HPV, none of tested subtypes (13,32,16 and 18) were positive (Fig. $3)$.

\section{Discussion}

Multifocal epithelial hyperplasia (MEH) is a rare entity in Asia, but it seems that in northern east of Iran it is not uncommon. No report of this disease exists in Iran.

This disease appears in the first and second decades of life and frequently affects children but other age groups may also be involved. $(3,7)$ We encountered a wide age range at onset ( 7 to 42 years).

The mean age of onset in our patients was 12 years that is more than previous reports (it has been 9-11 years) $(1,8)$. Although poverty has been suggested as a relative factor in many studies $(1-3,8)$, but all of our patients were from a middle socio economic group.

Affirming to most studies, the majority of patients were female $(7: 12)(1,2,7,8)$, although some studies have reported a male predilection $(2,11,12)$.

Familial involvement has been reported in most previous studies, but our patients didn't report such finding. Genetic predisposition (e.g. HLA-DR) and living in crowded conditions and use of common devices are possible causes of this concordance $(1,2)$.

Clinically, multiple flat top papules with a color similar to adjacent mucosa were observed in different oral sites $(1,2,8)$. In irritation areas whitish color due to keratosis was seen, as with previous reports $(8,10)$. The most frequent site of involvement in our cases was buccal mucosa and lip commisure which was compatible with most studies $(1,2,8)$, although lower lip mucosa, upper lip, ventral tongue and oropharynx have been reported in some series $(8,10)$. Buccal lesions were distributed along the occlusal plan. In addition, lower lip and lateral tongue were affected more frequently than upper lip and other tongue portions respectively, suggesting trauma as a contributing factor.

Viral etiology was established in 7:12 of patients and HPV13 has been the most associated subtype (5 cases), that was similar to other studies $(1,3,7,8,11)$. HPV32 was also positive in one patient. Although HPV13, 32 has been considered as etiologic factor in $\mathrm{MEH}$, but there are only few reports about presence of HPV32 in the literature. This may be due to heterogenisity of the populations $(8,13)$. Carlos in a study of 110 patients, noticed predilection of HPV13 for keratinized mucosa and subtype 32 for non keratinized mucosa (6).We couldn't assess this correlation because of small sample size. In one patient (Pt No.4) with strong reactivity for HPV, none of tested subtypes $(13,2,16$ and 18$)$ were positive. She was a healthy 12-year-old girl without any evidence of sexual abuse or activity or genital involvement. This issue in addition to absence of tongue lesions excluded condyloma acuminatum as a possibility.

There is one study that suggests HPV 24 as etiologic factor in long standing types of FEH (previously known as Heck's disease) (14). Malignant transformation has been reported in this case, although accuracy of clinical diagnosis in that case remains doubtful. In our cases no malignant changes was observed even after 22 years duration (Case No.8).

MEH is considered as a regressive lesion, $(1,3,7)$ but in our patients only 3:12 reported regression. Regression can be due to maturation of immune system in adulthood (1).

Duration of the lesions was between 2 months and 22 years. Catherine Flaitz, Ledesma-Montes and others reported duration of few months to 30 years, in their patients (1-4). Recurrence after regression is an occasional finding, although it sometimes depends on treatment modalities. We didn't see any recurrence in our regressed cases.

Differential diagnosis consists of condyloma acuminatum, verruca volgaris, papilloma, irritation fibroma, verusiform xantoma, juvenile papillomatosis and syndromes such as multiple endocrine neoplasia $ш$, neurofibromatosis, tuberous sclerosis, Cowden and GoltzGorlin.

The most confusing ones are condyloma acuminatum (C.A.) and irritation fibroma. In C.A. there are clustered papules with papillary surface in ventral tongue and floor of the mouth as a result of orogenital contact with an infected partner. MEH lesions tend to be flatter and more numerous and location of lesions is very characteristic.

If discrete papules are present, irritation fibroma should be considered in differential diagnosis. Pale appearance, increasing size and an obvious irritation can be helpful to distinguish fibroma from MEH.

\section{Conclusion}

Although MEH is considered a rare condition in Asia, in a 7 years period, 12 cases were observed in our area (northeast, Iran).Further epidemiologic studies are required to estimate the exact prevalence of this entity. 


\section{References}

1. Ledesma-Montes C, Vega-Memije E, Garcés-Ortíz M, CardielNieves M, Juárez-Luna C. Multifocal epithelial hyperplasia. Report of nine cases. Med Oral Patol Oral Cir Bucal. 2005;10:394-401.

2. Ledesma-Montes C, Garcés-Ortíz M, Hernández-Guerrero JC. Clinicopathological and immunocytochemical study of multifocal epithelial hyperplasia. J Oral Maxillofac Surg. 2007;65:2211-7.

3. Borborema-Santos CM, Castro MM, Santos PJ, Talhari S, AstolfiFilho S. Oral focal epithelial hyperplasia: report of five cases. Braz Dent J. 2006;17:79-82.

4. Flaitz CM. Focal epithelial hyperplasia: a multifocal oral human papillomavirus infection. Pediatr Dent. 2000;22:153-4.

5. Jayasooriya PR, Abeyratne S, Ranasinghe AW, Tilakaratne WM. Focal epithelial hyperplasia (Heck's disease): report of two cases with PCR detection of human papillomavirus DNA. Oral Dis. 2004;10:240-3.

6. Carlos R, Sedano HO. Multifocal papilloma virus epithelial hyperplasia. Oral Surg Oral Med Oral Pathol. 1994;77:631-5.

7. Ledesma MC, Torres VME, Garcés OM, López MD. Hiperplasia epitelial focal (enfermedad de Heck). Estudio clínico-patológico. Práctica Odontológica. 1992;13: 21-6.

8. González LV, Gaviria AM, Sanclemente G, Rady P, Tyring SK, Carlos R, et al. Clinical, histopathological and virological findings in patients with focal epithelial hyperplasia from Colombia. Int J Dermatol. 2005;44:274-9.

9. García-Corona C, Vega-Memije E, Mosqueda-Taylor A, Yamamoto-Furusho JK, Rodríguez-Carreón AA, Ruiz-Morales JA, et al. Association of HLA-DR4 (DRB1*0404) with human papillomavirus infection in patients with focal epithelial hyperplasia. Arch Dermatol. 2004;140:1227-31.

10. Binder B, Wieland U, Smolle J. Focal epithelial hyperplasia (Heck disease) in a black child. Pediatr Dermatol. 2007;24:E31-2.

11. Falaki F, Amir Chaghmaghi M, Pakfetrat A, Delavarian Z, Mozaffari PM, Pazooki N. Detection of human papilloma virus DNA in seven cases of focal epithelial hyperplasia in Iran. J Oral Pathol Med. 2009;38:773-6.

12. Akyol A, Anadolu R, Anadolu Y, Ekmekci P, Gürgey E, Akay N. Multifocal papillomavirus epithelial hyperplasia: successful treatment with $\mathrm{CO} 2$ laser therapy combined with interferon alpha-2b. Int J Dermatol. 2003;42:733-5.

13. Jimenez C, Correnti M, Salma N, Cavazza ME, Perrone M. Detection of human papillomavirus DNA in benign oral squamous epithelial lesions in Venezuela. J Oral Pathol Med. 2001;30:385-8.

14. Jablonska S. Demonstration of HPV 24 in long-standing Heck's disease with malignant transformation. Eur J Dermatol. 2000;10:235-6. 